\title{
Investigations on global buckling behaviour of concrete-filled double-skinned steel tubular columns
}

\author{
U. M. Sulthana ${ }^{a *}$, S. A. Jayachandran ${ }^{\mathrm{b}}$

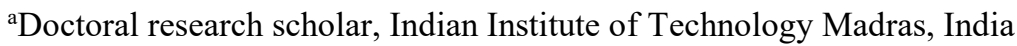 \\ ${ }^{\mathrm{b}}$ Associate Professor, Indian Institute of Technology Madras, India \\ *corresponding author, e-mail address: mashudha@gmail.com
}

\begin{abstract}
Concrete-Filled Double-skinned Steel Tubular columns (CFDST) are proved to possess exceptional structural resistance in case of fire and multi-hazard situations. This superior quality of CFDST makes it preferable in long column applications. However, studies on the long column behaviour of CFDST is very few, and their results are not in line with the behaviour of CFST long columns. Whereas, several researches on stub column CFDST shows that, the axial compression behaviour of CFDST is similar to CFST. In this paper, selected results (4 numbers of circular CFDST specimens) from a large test data is presented. Axial compression behaviour of long column CFDST specimens is studied, with non-dimensional slenderness $\lambda$ around 1.0, and hollowness ratio as the governing parameter for study. Test results namely, axial load carrying capacity, axial deformation and lateral deflection are presented in this paper. Numerical models are also developed and validated with the experimental results, to carry out more parametric studies. Further, the experimental axial capacity values are compared with modified capacity equations from EC4 and AISC. Results show that extended EC4 and AISC equations gives conservative predictions for CFDST column even in the long column range. Moreover, the initial imperfections in the specimen and their corresponding boundary conditions for load application, are found to be governing parameters in long column buckling study.
\end{abstract}

Keywords: CFDST; long column; composite column; global buckling; initial imperfections.

\section{Introduction}

Concrete filled double skinned steel tubes (CFDST), a variant of concrete filled steel tubes (CFST) have been studied by various researchers [1-5] in the recent past. The concrete confinement effect in CFDST is rigorously evaluated by these authors, studies [6-9] have used numerical means to determine the confinement effect, which is validated against experimental results. Here, concrete confining stress is given utmost priority in research findings, as CFST got the limelight due to its inherent ability to enhance the core concrete strength at higher strain levels. Even though, the concrete confining stress is found to be lesser in CFDST compared to CFST sections under axial compression, the absolute strength and stiffness are higher due to its high steel area ratio. Further, CFDST has many practical advantages over
CFST, by possessing large member ductility [10, 11], fire and corrosion resistance $[12,13]$, and ease in connection design $[14,15]$.

In most of the above research works, short column $(\lambda \approx 0.2)$ behaviour is studied, in order to understand the concrete confining action. However, in practical applications, slender members will be used, as the axial load carrying capacity is high for small cross-sections. Many studies are found for long column CFST sections [16-18]. International standards like EC4 and AISC accounts for the length effects in CFST columns similar to a steel column, except that, $E I_{\text {eff }}$ is used in finding the critical buckling loads. This approach has been validated through a large set of experimental data [17] and it is found to be conservative. Recently, few experimental studies were carried out for CFDST long columns [19-21] to understand their behaviour 
and to evaluate the member stability approach as used for CFST. It is found that the present approach over estimates the load carrying capacity.

The present study was started with an objective to understand the long column behaviour of CFDST in a comprehensive manner. Experiments were designed carefully on a wide range of cross-sections, with governing parameters like, shape of the cross-section, hollowness ratio and concrete strength. Test result shows that the long column bahaviour of CFDST is as same as that of CFST columns, with significant conservativeness.

Here, test results of selected 4 circular columns are reported. The procedure adopted for conducting the test, and the test results are explained in detail. Numerical model is developed using ABAQUS and compared with test results. The test load capacity is also compared with EC4 and AISC axial capacity formulae, modified for CFDST cross-section.

\section{Experimental program}

The primary objective of this program is to study the global buckling in CFDST long columns. Therefore, tubes sizes are selected such that the specimens fail by global buckling under axial compression. A nominal diameter of 165.1 $\mathrm{mm}$ is selected as the outer steel tube, with three different inner steel tubes sizes to develop hollowness ratios of, $70 \%, 50 \%$ and $20 \%$ (Fig. 1). Length of all the specimens is $3600 \mathrm{~mm}$. The cross-sectional geometric and material properties of the specimens are shown in Table 1. Material property of the steel tubes is found by fabricating and testing the coupons as per ASTM E8-04. The average yield strength of the tension coupon is $520 \mathrm{~N} / \mathrm{mm}^{2}$. Concrete compressive strength was found by casting concrete cubes (per IS:516-1959), from each concrete batch prepared for filling the specimens. Mean concrete cube strength $\left(\mathrm{f}_{\mathrm{cm}}\right)$, is reported here in $N / \mathrm{mm}^{2}$. $D_{0}$ and $D_{i}$ are the measured diameters (in $\mathrm{mm}$ ) of outer and inner steel tubes respectively, and $t_{o}$ and $t_{i}$ are the measured diameters (in $\mathrm{mm}$ ) of outer and inner steel tubes, respectively.

Table 1. Geometrical and material properties.

\begin{tabular}{lccccc}
\hline Sp. ID & $\mathbf{D}_{\mathbf{o}}$ & $\mathbf{t}_{\mathbf{o}}$ & $\mathbf{D}_{\mathbf{i}}$ & $\mathbf{t}_{\mathbf{i}}$ & $\mathbf{f}_{\mathbf{c m}}$ \\
\hline $\mathrm{C} 0-00$ & 165.84 & 5.06 & & & 58.61 \\
$\mathrm{CC}-20$ & 166.34 & 5.24 & 33.70 & 4.00 & 57.94
\end{tabular}




\subsection{Testing of specimens}

Specimens were tested in upright position in a compression testing frame of $6000 \mathrm{kN}$ capacity. Compressive Load was applied concentrically using a hydraulic jack of $5000 \mathrm{kN}$ capacity. The specimen ends are attached to stiff end plates with a groove and roller bar arrangement to develop a hinge-hinge boundary condition. Instrumentation was designed such that the load, axial deformation, lateral displacement at the mid-height of the specimen are recorded continuously. Strain gauges were also pasted at the mid-height to record the axial and circumferential strain during the loading process. Load was applied at a rate of $1 / 15^{\text {th }}$ of assumed ultimate load per minute. Test was terminated with the failure of specimens, which is essentially global buckling. Typical failure pattern of the specimen is depicted in Fig. 4.
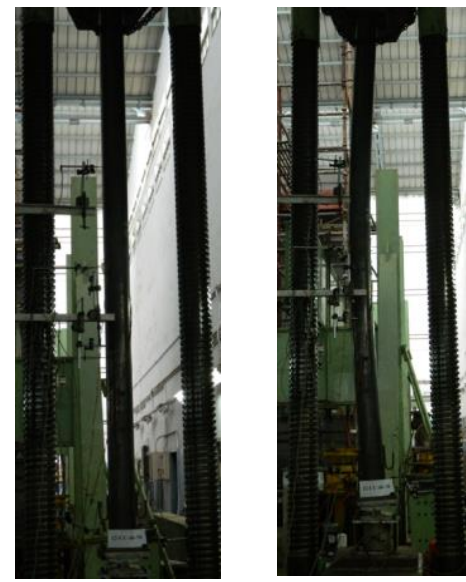

Fig. 4. Typical specimen before and after loading.

\subsection{Test results}

All the specimens failed by global buckling, as expected. Load versus axial deformation and lateral deflection are shown in Fig. 5 and Fig.6, respectively.

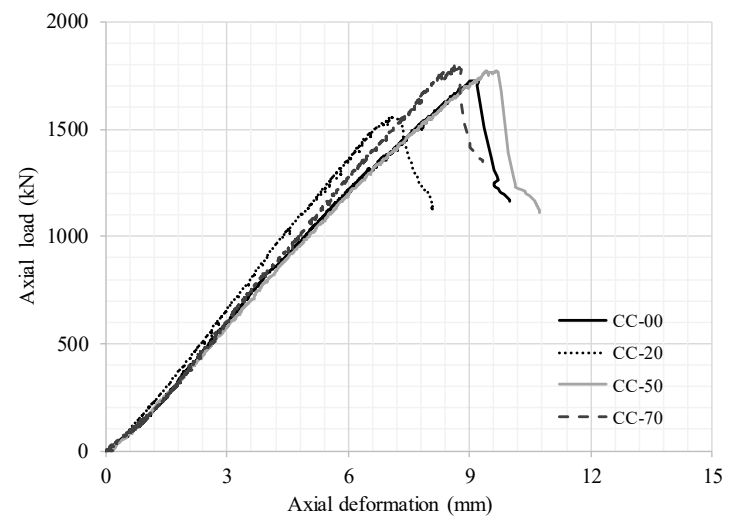

Fig. 5. Axial load versus axial deformation curves.

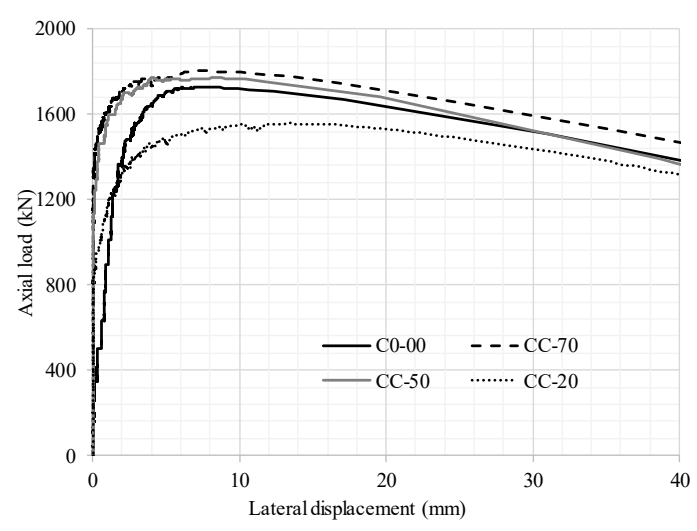

Fig. 6. Axial load versus lateral deflection.

The measured axial loads are compared with axial capacity equations specified in EC4 and AISC, in Table 2. It could be observed that the test capacity is much higher than the predicted values using EC4 and AISC specifications. This is synonymous with test data reported by [17], where the CFST long column capacity predictions were reported to be highly conservative in nature. However, it is totally in contrast to the reported test data for long column CFDST [19,20,21]. Most governing reason for this variation in the results is due to the low initial imperfection of tested specimens in the present study.

Table 2.Measured axial load capacity compared with EC4 and AISC specifications modified for CFDST long columns.

\begin{tabular}{lccccc}
\hline Sp. ID & P test & $\mathbf{P}_{\text {EC4 }}$ & $\mathbf{P}_{\text {AISC }}$ & $\mathbf{P}_{\text {EC4 }} / \mathbf{P}_{\text {test }}$ & $\mathbf{P}_{\text {AISC }} / \mathbf{P}_{\text {test }}$ \\
\hline C0-00 & 1726 & 1285 & 1294 & 0.76 & 0.76 \\
CC-20 & 1557 & 1350 & 1371 & 0.83 & 0.85 \\
CC-50 & 1771 & 1362 & 1386 & 0.76 & 0.77 \\
CC-70 & 1803 & 1503 & 1532 & 0.87 & 0.88 \\
\hline
\end{tabular}

\section{Numerical study}

ABAQUS commercial software is used to develop the numerical model of the specimens. Geometric as well as material non-linearities are considered in the model to replicate the postbuckling behavior of the specimens from experiments.

\subsection{Modelling criteria}

The specimen model is generated in five parts for CFDST and four parts for CFST specimen, in 3D space. The inner and outer steel tubes are modelled using 4-noded shell elements with reduced integration $(\mathrm{S} 4 \mathrm{R})$, as the strain variation 
across the thickness could be assumed to be uniform $(D / t>20)$. The concrete in-fill is modelled using 8-noded brick elements, C4D8R. The mesh size of $12.5 \mathrm{~mm}$ is maintained at the cross-section level and $25 \mathrm{~mm}$ along the length based on convergence study found in literature [22]. Two end plates are modelled at top and bottom of the specimens to distribute the applied loads evenly to the specimen surface, again using C4D8R elements. Very stiff material properties $\left(\mathrm{E}=10^{12} \mathrm{~N} / \mathrm{mm}^{2}, v=0.00001\right)$ are considered for end plates, so that it undergoes neglible deformation while loading.

A tri-linear stress-strain curve is adopted for material model of steel tubes, where the pivotal inputs are taken from the tension test data. For the concrete material model, confined stressstrain model recommended [8] for CFDST with CHS in CHS cross-section is adopted. DruckerPrager yield criteria is applied for the concrete plasticity model, with an angle of friction of $20^{\circ}$ and a flow ratio of 0.8 . Steel tubes are connected to the end plates by shell-to-solid coupling, while tie constraint is used for concrete core to end plate connection. End plates act as master surface while in contact with steel tubes and concrete surface. Whereas, for the interface modelling of steel tubes with concrete core, the steel tube is assigned as the master surface and concrete core as the slave, during loading process. Penalty friction of 0.25 , and hard contact are given as tangential and normal contact properties respectively for the contact modelling. The surface is allowed to separate after contact.

Loading and boundary conditions are applied at the centerline of the two end plates as shown in Fig. 7, to simulate the test loading condition. Static-general algorithm is chosen for analyzing the model with contact stabilization, to avoid convergence issues. The nodes at the centerline of the base plate is selected and restrained from translating in $\mathrm{x}, \mathrm{y}$ and $\mathrm{z}$ directions, and rotation about z-dir is also restrained. Similar boundary condition is applied at the top plate, except for translational restraint in the z-dir, to facilitate loading. Initial imperfections are incorporated from a previously run buckling analysis model. Fundamental eigenmode is adopted as the initial buckled shape with a maximum deformation at the mid-height of the specimen as L/3000. Pressure overclosures are applied at the steelconcrete interfaces at the beginning of the analysis.

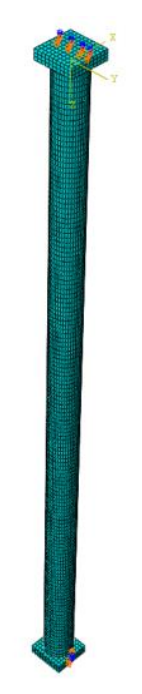

Fig. 7. Boundary condition applied over the centerline of end plate.

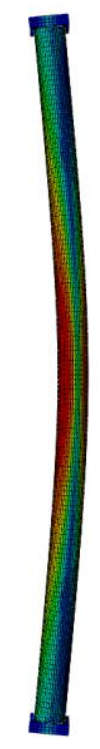

Fig. 8. Deflected shape of simulated specimen at failure load.

The deflected shape of a typical model is shown in Fig. 8, which is global buckling similar to the failure pattern observed from experiments.

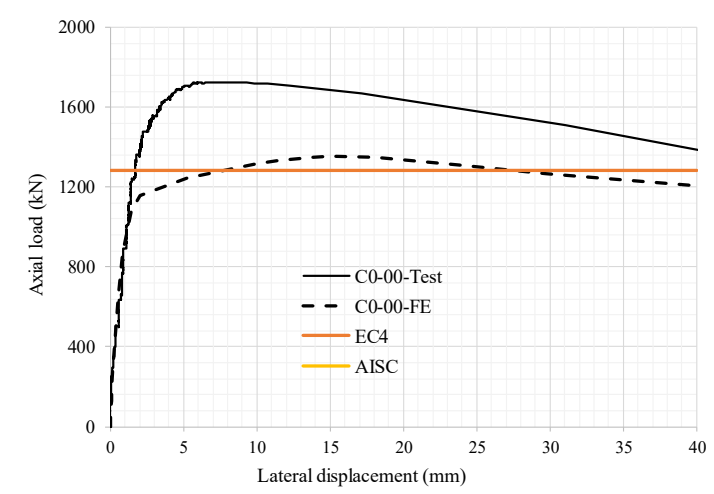

(a) 


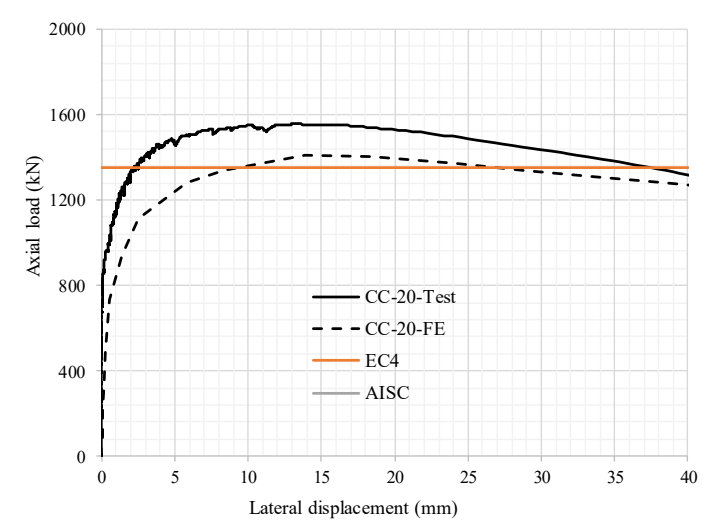

(b)

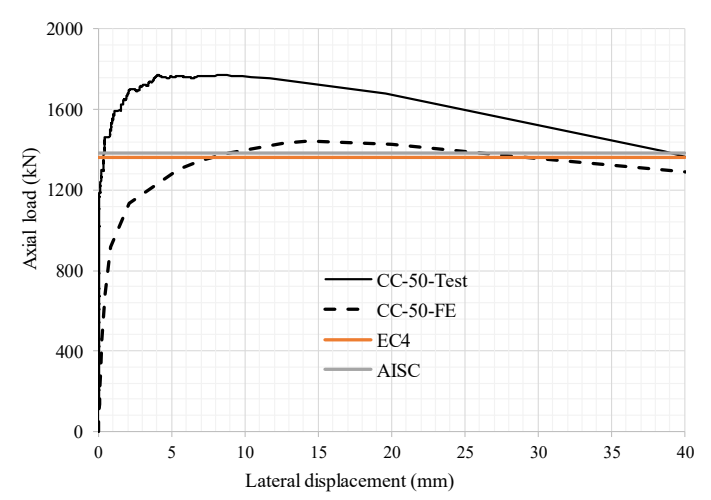

(c)

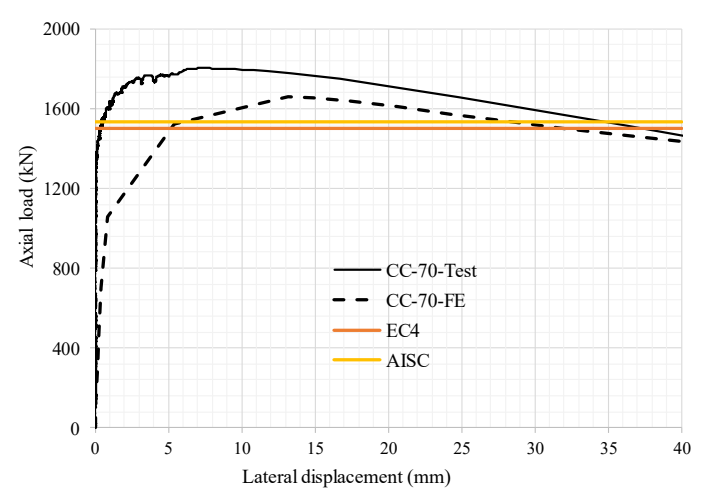

(d)

Fig. 9. Axial load versus lateral displacement curves compared with numerical results and analytical predictions

(a) C0-00; (b) CC-20; (c) CC-50; (d) CC-70.

Axial load vs. lateral displacement curves extracted from the numerical results are compared with the test results for the selected specimens as presented in Figs. 9(a-d). It should be noted that the initial stiffnesses and the overall behavior from tests, and numerical model matches well. However, the ultimate loads from experiments are consistently high in all the specimens compared to the numerical values. It should be noted that the actual initial imperfection in the selected specimens was outof-plumb, whereas, the fundamental buckling mode for hinge-hinge boundary condition is outof-straightness. This is the reason for the mismatch between the test and numerical results. Further, the increase in load carrying capacities observed in experiments for CFDST, is lesser compared to CFST specimen, which could be due to the low confinement in CFDST compared to CFST. Therefore, it is inferred that the inelasticity in concrete which has set before the overall elastic buckling, has triggered the confinement action at the cross-section level, as the actual initial imperfection is not the fundamental buckling mode for the selected boundary condition. This is the reason for the highly conservative capacity predictions by EC4 and AISC specifications as well. Nevertheless, for practical applications, it is important to study the buckling behaviour of long columns with perturbations in its fundamental buckling mode. Therefore, it recommended using numerical approach to study the member effects in strength prediction.

\section{Conclusions}

Long column behaviour of concrete filled double-skinned steel tubes (CFDST) are studied by conducting experiments and developing numerical models. Observations from the studies are enumerated as below.

- The long column behavior of CFDST is similar to CFST section, in experimental as well as numerical studies.

- Test ultimate capacity for all the specimens is very high compared to numerical results and analytical predictions, which has happened due to concrete confinement action.

- Test specimens has undergone concrete confinement, as the actual initial imperfection is not the fundamental buckling mode of the selected test boundary condition.

- Axial load predictions using EC4 and AISC specifications could be extended for CFDST long columns also, with good degree of conservativeness.

\section{References}

[1] Han LH, Tao Z, Huang H, Zhao XL, Concretefilled double skin (SHS outer and CHS inner) steel tubular beam-columns, Thin-Walled Structures 2004; 42: 1329-1355. 
[2] Tao Z, Han HL, Zhao XL, Behaviour of concrete-filled double skin (CHS inner and CHS outer) steel tubular stub columns and beamcolumns. Journal of Constructional Steel Research 2004; 60: 1129-1158.

[3] Elchalakani M, Zhao XL, Grzebieta, R. Tests on concrete filled double-skin (CHS outer and SHS inner) composite short columns under axial compression. Thin-Walled Structures 2002; 40: 415-441.

[4] Uenaka K, Kitoh H, Sonoda K. Concrete filled double skin circular stub columns under compression. Thin-Walled Structures 2010; 48: 19-24.

[5] Uenaka K. CFDST stub columns having outer circular and inner square sections under compression. Journal of Constructional Steel Research 2016; 120: 1-7.

[6] H. Huang, L.-H. Han, Z. Tao, X.-L. Zhao, Analytical behaviour of concrete-filled double skin steel tubular (CFDST) stub columns, Journal of Constructional Steel Research 66 (2010) 542-555.

[7] $\mathrm{Hu} \mathrm{H}, \mathrm{Su} \mathrm{S}$. Nonlinear analysis of short concrete-filled double skin tube columns subjected to axial compressive forces. Marine Structures 2011; 24: 319-337.

[8] Liang QQ. Nonlinear analysis of circular double-skin concrete-filled steel tubular columns under axial compression. Engineering Structures 131: 639-650.

[9] Pagoulatou M, Sheehan T, Dai XH, Lam D. Finite element analysis on the capacity of circular concrete-filled double-skin steel tubular (CFDST) stub columns, Engineering Structures 2014; 72: 102-112.

[10] Hsiao P, Hayashi KK, Nishi R, Lin X, Nakashima M. Investigation of concrete-filled double-skin steel tubular columns with ultrahigh-strength steel. Journal of Structural Engineering (ASCE) 2014; 141(7): 1-8.

[11] Zhang F, Wu C, Zhao X, Li Z, Heidarpour A, Wang H. Numerical modeling of concrete-filled double-skin steel square tubular columns under blast loading Journal of Structural Engineering (ASCE) 2015; 29(6): 1-8.

[12] Romero ML, Espinós A, Portolés JM, Hospitaler H, Ibañez C. Slender double-tube ultra-high strength concrete-filled tubular columns under ambient temperature and fire. Engineering Structures 2015; 99: 536-545.

[13] Guo F, Khoo W, Al-Saadi S, Li YL, Raman RKS, Zhao XL. Preliminary study on durability of FRP and stainless steel in seawater and sea sand concrete (SWSSC) environment. 11th International Conference in Advances in Steel-
Concrete Composite Structures; 2015: 342-349.

[14] Espinos A, Romero ML, Hospitaler A, Pascual AM, Albero V. Advanced materials for concrete-filled tubular columns and connections. Structures 2015; 4:105-113.

[15] Li W, Ren QX, Han LH, Zhao XL. Behaviour of tapered concrete-filled double skin steel tubular (CFDST) stub columns. Thin-Walled Structures 2012; 57: 37-48.

[16] Kato B. Column curves of steel-concrete composite members. Journal of Constructional Steel Research 1996; 39: 121-135.

[17] Han LH. Tests on concrete-filled steel tubular columns with high slenderness ratio. Advances in Structural Engineering 2000; 337-344.

[18] Perea T, Leon RT, Hajjar JF, Denavit MD. Fullscale tests of slender concrete-filled tubes: Interaction behavior. Journal of Structural Engineering 2013; 139(7): 1-14.

[19] Romero ML, Portolés JM, Espinós A, Pons D. Influence of ultra-high strength concrete on circular concrete-filled dual steel columns. 11th International Conference in Advances in SteelConcrete Composite Structures; 2015: 342-349.

[20] Essopjee Y, Dundu D. Performance of concretefilled double-skin circular tubes in compression. Composite Structures 2015; 133: 1276-1283.

[21] Sulthana UM, Jayachandran SA. Axial compression behaviour of long concrete-filled double-skinned steel tubular columns. Structures 2017; 9: 157-164.

[22] Tao Z, Wang Z, Yu Q. Finite element modelling of concrete-filled steel stub columns under axial compression. Journal of Constructional Steel Research 2013; 89: 121-131. 